\title{
Impaired glucose tolerance and diabetes mellitus in a suburban Sri Lankan community
}

\author{
Devaka J.S. Fernando*, Sisira Siribaddana and Deepthika de Silva
}

Sri Jayawardenepura General Hospital, Talapathpitiya, Nugegoda, Sri Lanka

\begin{abstract}
Summary: The prevalence of impaired glucose tolerance and diabetes mellitus was studied in a suburban Sri Lankan community using 1985 WHO criteria. Oral $75 \mathrm{~g}$ glucose tolerance tests were performed on 633 subjects aged 30-64 years. The age-standardized prevalence rates for diabetes mellitus were 5.02 (95\% CI 3.59-6.43) and impaired glucose tolerance 5.27 (95\% CI 3.74-6.78). A total of $21 \%$ of diabetic patients were not known to have diabetes and were diagnosed for the first time during the survey. Obesity was more common $(P<0.05)$ in diabetic patients $(21 \%)$ when compared to non-diabetic subjects (10.5\%). Diabetes mellitus is a common health problem in Sri Lanka, and there is a need for developing national policies for its prevention and control.
\end{abstract}

\section{Introduction}

Diabetes is a significant public health problem in the developed world and is thought to be a common health problem associated with urbanization, development and adoption of modern ('Westernized') lifestyles. ${ }^{1}$ As increasing numbers of developing nations acquire such lifestyles during the process of development, non-communicable diseases such as diabetes mellitus have increased in parallel with economic development. ${ }^{2}$ The World Health Organisation (WHO) estimates that there are 40 million people with diabetes in developing countries and that the number is expected to increase to 65 million by the year $2000 .{ }^{3}$ However, until recently, chronic non-communicable diseases were seen as minor secondary concerns in the national health plan when compared to communicable diseases.

In Sri Lanka, a decline in mortality from communicable diseases may result in chronic noncommunicable diseases having a significant impact on mortality and morbidity rates. Changes in demographic profile, increasing urbanization, changes in lifestyle, diet and increasing life expectancy ${ }^{3}$ are all expected to contribute to an increase in the prevalence of diabetes mellitus. Developing countries such as Sri Lanka are expected to face the double burden of both communicable and noncommunicable diseases in the future. ${ }^{4}$

The WHO has recently advocated the develop-

Correspondence: D.J.S. Fernando, M.D., M.R.C.P., M.Sc., 53A Flower Road, Colombo 7, Sri Lanka.

*Present address: General Hospital, Colombo, Sri Lanka.

Accepted: 11 November 1993 ment of national programmes for diabetes mellitus. ${ }^{5}$ Knowledge about prevalence of diabetes is an essential prerequisite to developing an effective programme for the prevention and control of non-communicable diseases. ${ }^{5}$

There are no published studies on prevalence of diabetes mellitus in Sri Lanka. We therefore conducted a study to assess the prevalence of diabetes mellitus in a suburban population in Sri Lanka.

\section{Patients and methods}

The target population comprised adults in the defined electoral area (area 8 Maharagama, a suburb of Colombo) aged 30-64 years. Of the 4,334 persons in the register, 2,974 were within the target population. A simple random sample was obtained from the electoral list by using a table of random numbers. A total of 700 individuals (337 men) were selected to participate in this survey: 633 (312 men) agreed to participate, 65 of whom were Tamil, 12 Muslim and the rest Sinhala $(88 \%$ Sinhala, $10.3 \%$ Tamil). The relative proportions for the different ethnic groups were similar to those at national level. The participants attended a hospital clinic located within 3 miles of their homes. They were instructed to come in the morning after a 12 hour overnight fast, after at least 3 days of unrestricted diet (carbohydrate intake $>150 \mathrm{~g}$ ), usual levels of physical activity and abstaining from smoking. The height without shoes was recorded in $\mathrm{cm}$ and the weight without shoes was recorded in $\mathrm{kg}$. The body mass index was calculated according to the formula BMI = weight $(\mathrm{kg}) /$ height $^{2}(\mathrm{~m})\left(\mathrm{kg} / \mathrm{m}^{2}\right)$. Obesity was defined as a 
body mass index $>25$ in women and $>27$ in men in a study on prevalence of diabetes in South India. ${ }^{6}$ We used the same criteria. A $75 \mathrm{~g}$ 2-hour glucose tolerance test was performed. Glucose was measured in venous whole blood using the glucose oxidase method and a Cobas Mira photoanalyser in the hospital laboratory. Random samples of blood for glucose estimations were measured in duplicate. The correlation coefficient for duplicate readings was 0.992 and coefficient of variation was $1.7 \%$.

Diabetes mellitus and impaired glucose tolerance were defined according to the WHO criteria. ${ }^{1}$ Patients currently on oral anti-diabetic agents or insulin therapy were classified as diabetic if initial criteria for diagnosis were stated in hospital discharge letters. If no data were available, oral hypoglycaemics were withdrawn and patients retested after 3 days. Patients treated with insulin were labelled as diabetic and were not subjected to glucose tolerance tests.

The prevalence of diabetes may vary with the age structure of a sample. In order to ensure comparability between different studies it is helpful to express prevalence as an age-standardized rate for a standard population. This would then represent the prevalence that would be observed in a reference population. A hypothetical standard population age structure is used in many multinational comparative studies. The 5-year agespecific rates for the sample were calculated and standardization performed by the direct method against the standard world population of Segi. ${ }^{7}$ Results were expressed as age-standardized rates with $95 \%$ confidence intervals. $^{8}$ Comparison of crude prevalences of obesity in diabetic and nondiabetic groups was by chi-squared analysis.

\section{Results}

The crude prevalence of diabetes in the population studied was 5.2 and the age-adjusted prevalence 5.02 (95\% CI 3.59-6.43). The age-adjusted prevalence rate for impaired glucose tolerance (IGT) was 5.27 (95\% CI 3.74-6.78). The prevalence of diabetes and IGT increased with age (Table I). Eighteen of the 33 diabetic patients and 20 of the 34 subjects with IGT were women. However, the sample studied is too small to comment on gender-specific prevalence rates or prevalence rates for different ethnic/racial groups.

Twenty-six patients had previously diagnosed diabetes. Two were treated with insulin. Six patients in whom criteria for diagnosis were not documented were retested with glucose tolerance tests 3 days after withdrawal of oral hypoglycaemic agents. All had glucose tolerance test results in the diabetic range. Seven $(21 \%)$ diabetic patients were
Table I The prevalence of diabetes mellitus and impaired glucose tolerance

\begin{tabular}{lccccc}
\hline & & \multicolumn{5}{c}{ Crude prevalence (\%) } \\
Age & No. tested & DM & IGT & DM & IGT \\
\hline $30-34$ & 97 & 1 & 1 & 1.03 & 1.03 \\
$35-39$ & 93 & 2 & 3 & 2.15 & 3.23 \\
$40-44$ & 91 & 5 & 6 & 5.49 & 6.59 \\
$45-49$ & 97 & 6 & 7 & 6.19 & 7.22 \\
$50-54$ & 98 & 7 & 5 & 7.14 & 5.1 \\
$55-59$ & 81 & 7 & 6 & 8.64 & 7.41 \\
$60-64$ & 76 & 5 & 6 & 6.58 & 7.89 \\
Total & 633 & 33 & 34 & 5.21 & 5.37
\end{tabular}

Age-adjusted prevalence rates

$\begin{array}{ll}\text { DM } & 5.02(95 \% \text { CI } 3.59-6.43) \\ \text { IGT } & 5.27(95 \% \text { CI } 3.74-6.78)\end{array}$

DM $=$ diabetes mellitus; $\mathbf{I G T}=$ impaired glucose tolerance.

not previously known to have diabetes. Two of the patients diagnosed as having diabetes for the first time had clinical evidence of retinopathy at the time of diagnosis. One had neuropathic foot ulcers.

A strong relationship existed between diabetes mellitus and excess body weight. The prevalence of obesity in diabetic patients $(21 \%)$ was higher $(P<0.05)$ than in non-diabetic individuals $(10.5 \%)$.

\section{Discussion}

The prevalence of diabetes mellitus in Sri Lankan communities has not been previously documented. A recent review on the prevalence of diabetes in different regions ${ }^{7}$ reported that the prevalence of diabetes in rural Sri Lanka was $5.1 \%$ and IGT $7.7 \%$. The data were from an unpublished study. Comparison between prevalence rates in different countries is difficult because of the varying sampling techniques used and the different age distribution of populations. We have used methods (sampling technique and age groups studied) used by the WHO ad hoc committee on global prevalence of diabetes, ${ }^{7,9}$ and documented for the first time the high prevalence of diabetes mellitus and IGT in a suburban Sri Lankan population.

Recent publications have highlighted the appearance of an epidemic of diabetes in developing countries. ${ }^{9}$ A high prevalence of IGT indicates a high risk of subsequent development of diabetes. Hence, the combined prevalence of diabetes and IGT is a useful measure of the public health impact of diabetes. ${ }^{10} \mathrm{~A}$ high IGT rate with low NIDDM suggests a potential for an epidemic of diabetes with westernization and increasing urbanization while a rising diabetes rate indicates a developing epidemic. The ratio is higher in the rural sample 
and lower in the urban sample, indicating that the prevalence of diabetes may have increased with urbanization and that the anticipated epidemic of diabetes mellitus has already affected suburban Sri Lanka.

It was previously reported that diabetes was more common amongst men in Sri Lanka. ${ }^{11,12}$ This study shows a higher prevalence in women. It is possible that the low prevalence reported from hospital-based studies in the past was due to low attendance of females at hospital clinics. No subjects with hyperglycaemia had a BMI $<18 \mathrm{~kg} / \mathrm{m}^{2}$ indicating that malnutrition-related diabetes mellitus was uncommon in this population.

The increase in the prevalence of diabetes in the older age group has been well documented..$^{13-15} \mathrm{~A}$ trend towards increasing prevalence with age was seen but the truncated sample used for this study does not permit any conclusions to be drawn about diabetes in the elderly.

\section{References}

1. WHO Diabetes Mellitus. Report of a WHO Study Group. Technical report series, no. 727. World Health Organisation, Geneva, 1985.

2. Ekoe, J.M. Diabetes Mellitus: Aspects of the Worldwide Epidemiology of Diabetes Mellitus and its Complications. Elsevier, Oxford, 1988.

3. Ching, L.H. Mobilisation against diabetes. In: Larkins, R., Zimmet, P. \& Chisholm, D. (eds) Diabetes 1988. Elsevier, Amsterdam, 1989, pp. 873-876.

4. Skrabalo, Z. \& Katona, G. Problems of the developing nations. In: Krall, L.P. (ed.) World Book of Diabetes in Practice. Vol. 2. Elsevier, Amsterdam, 1986, pp. 267-275.

5. WHO Division of Non-communicable Diseases and Health Technology. Guide-lines for the Development of a National Programme for Diabetes Mellitus. WHO/DBO/DM/91.1. World Health Organisation, Geneva, 1991.

6. Ramachandran, A., Jali, M.V., Mohan, V., Senehalatha, C \& Viswanathan, M. High prevalence of diabetes in an urban population in South India. Br Med J 1988, 297: 587-590.

7. King, H. \& Rewers, M. Global estimates for prevalence of diabetes mellitus and impaired glucose tolerance in adults. Diabetes Care 1993, 16: 157-177.

8. Morris, J.E. \& Gardner, M.J. Calculating confidence intervals for relative risks (odds ratios) and standardised ratios and rates. $\mathrm{Br}$ Med J 1988, 296: 1313-1316.
The finding of $21 \%$ diabetic individuals previously not known to have diabetes is a cause for concern. It is well known that prolonged asymptomatic hyperglycaemia can lead to patients presenting with retinal and vascular complications. ${ }^{16}$ This indicates an urgent need for the development of an appropriate screening programme.

We conclude that diabetes mellitus is a common health problem in Sri Lanka and that health planners and policy makers should follow the WHO guidelines ${ }^{5}$ to develop national policies for the prevention and control of diabetes.

\section{Acknowledgements}

We are grateful to MSD International and Mansell Ceylon for a research grant.

9. King, H. \& Rewers, M. Diabetes is now a third world problem. Bull WHO 1991, 69: 643-648.

10. Dowse, G., Zimmett, P. \& King, H. Relationship between prevalence of impaired glucose tolerance and NIDDM in a population. Diabetes Care 1991, 14: 968-974.

11. Fernando, H.M. Discussion on 'Diabetes in the tropics'. $\mathrm{Br}$ Med J 1907, ii: 1060.

12. Weerasinghe, H.D. The epidemiology of diabetes mellitus. Ceylon Med J 1967, 2: 160-175.

13. Fernando, D.J.S. \& Boulton, A.J.M. Diabetes management in old age. In: Brocklehurst, J.C., Tallis, N. \& Fillit, H. (eds) Textbook of Geriatric Medicine and Gerontology, 4th edn. Churchill Livingstone, London, 1992, pp. 729-738.

14. Sinclair, A.J. \& Barnett, A.H. Special needs of elderly diabetic patients. Br Med J 1993, 306: 1142-1143.

15. Fernando, D.J.S., de Silva, C.E., Nanayakkara, S.F.R. \& Samarasinghe, H.H.R. Diabetes in the elderly in a developing country. Diabetes Res Clin Pract 1992, 15: 245-246.

16. Walsh, C.H., Solar, M.G. \& Fitzgerald, M.G. Association of foot lesions with retinopathy in patients with newly diagnosed diabetes. Lancet 1975 , ii: 878-880. 